\title{
Decompressive Craniectomy: Contralateral Lesions and Metabolic Abnormalities
}

\author{
F.A. Zeiler, M. West
}

\begin{abstract}
Objective: To define the incidence of new contralateral intracranial lesions following decompressive hemicraniectomy for blunt traumatic brain injury, and explore the potential association with metabolic factors that contribute to coagulopathy. Methods: We retrospectively reviewed the records and imaging of all patients treated with hemicraniectomy for blunt traumatic brain injury at our institution from May 2007 up to and including January 2012. Results: Twenty patients were identified during the time period to have undergone decompressive craniectomy for blunt head injury. The average age and Glasgow Coma Scale on presentation was 44.1 years (range: $19-72$ years) and 6.5 (range: 3 - 14) respectively. All but one patient presented with an extra-axial hematoma as their surgical indication for craniectomy. Seven patients (35.0\%) developed new contralateral lesions post-craniectomy. The average peri-operative $\mathrm{pH}$, bicarbonate $\left(\mathrm{HCO}_{3}\right)$ and hematocrit $(\mathrm{HCT})$ levels for those with new contralateral lesions were lower than those without new lesions. Five of the seven patients (71.4\%) with new lesions had abnormalities on their laboratory results that have been know to be attributable to coagulopathy, with four (57.1\%) having two or more abnormal results. Eight of $13(61.5 \%)$ patients without new lesion had laboratory abnormalites, with five (38.5\%) having two or more abnormalities identified. Conclusions: The incidence of new contralateral lesions post-craniectomy for blunt head injury is $35.0 \%$ in our experience. There is an association between the metabolic derangements linked to trauma related coagulopathy and the formation of new lesions.
\end{abstract}

RÉSUMÉ: Craniectomie de décompression : lésions controlatérales et anomalies métaboliques. Objectif : Le but de l'étude était de préciser l'incidence de nouvelles lésions intracrâniennes controlatérales suite à une hémicraniectomie de décompression réalisée suite à une contusion cérébrale et d'explorer une association potentielle avec des facteurs métaboliques qui contribuent à une coagulopathie. Méthode : Nous avons revu rétrospectivement les dossiers et l'imagerie de tous les patients ayant subi une craniectomie pour une contusion cérébrale dans notre institution entre mai 2007 et la fin de janvier 2012. Résultats : Vingt patients ont subi une craniectomie de décompression pour une contusion cérébrale au cours de cette période. L'âge moyen des patients était de 44,1 ans (écart de 19 à 72 ans) et leur score moyen à l'échelle de Coma de Glasgow était de 6,5 (écart de 3 à 14). Chez tous sauf un l'indication chirurgicale de la craniectomie était la présence d'un hématome extra-axial. Sept patients (35,0\%) ont présenté de nouvelles lésions controlatérales suite à la craniectomie. Le niveau moyen du pH, du bicarbonate $\left(\mathrm{HCO}_{3}\right)$ et de l'hématocrite (HCT) péri-opératoire chez ceux qui présentaient de nouvelles lésions controlatérales était plus bas que celui des patients qui n'ont pas présenté de nouvelles lésions. Cinq des sept patients $(71,4 \%)$ qui ont présenté de nouvelles lésions avaient des résultats de laboratoire anormaux connus comme étant attribuables à une coagulopathie, dont $4(57,1 \%)$ avaient deux résultats anomaux ou plus. Huit patients sur $13(61,5 \%)$ sans nouvelle lésion présentaient des anomalies de laboratoire et $5(38,5 \%)$ avaient 2 anomalies ou plus. Conclusions : L'incidence de nouvelles lésions controlatérales après une craniectomie pour contusion cérébrale était de 35,0\% dans notre série de patients. Il existe une association entre les désordres métaboliques en relation avec une coagulopathie liée au traumatisme et l'apparition de nouvelles lésions.

Can J Neurol Sci. 2014; 41:350-356

Decompressive craniectomy for traumatic brain injury is fraught with complications. Progression of existing contusions, evolution of contralateral lesions, external cerebral herniation, subdural collections, shunt dependent hydrocephalus and infection have all been described ${ }^{1-3}$.

New contralateral mass lesions after craniectomy have been described in many case series ${ }^{1,4-6}$. Potentially up to $7 \%$ of patients undergoing decompressive craniectomy for trauma will display new contralateral epidural hematomas (EDH), usually associated with underlying skull fracture ${ }^{7}$. Given these trauma patients typically present in extreme states, one could raise the concern of coagulopathy contributing to the incidence of new contralateral lesions post craniectomy.
There exists a negative correlation between coagulation profile and outcomes in severe head trauma ${ }^{8-10}$, with Stein et al ${ }^{11}$ describing an association between coagulation status and progressive or new intracranial lesions on follow-up imaging.

From the Section of Neurosurgery, Dept of Surgery (FAZ, MW), University of Manitoba, Winnipeg, Manitoba; Section of Neurocritical Care (FAZ), Montreal Neurological Institute, McGill University, Montreal, Quebec, Canada.

Received September 10, 2013. Final Revisions Submitted November 4, 2013. Correspondence to: Frederick A Zeiler, Section of Neurosurgery, University of Manitoba, Health Sciences Center, GB-1 820 Sherbrook Street, Winnipeg, Manitoba, R3A1R9, Canada. Email: umzeiler@cc.umanitba.ca. 
Acidosis, hemodilution, hypocalcemia, inflammation and thrombocytopenia have all been described as factors contributing to coagulopathy in trauma patients ${ }^{12,13}$.

Within this study we define our institutional incidence of new contralateral lesions post decompressive craniectomy for blunt traumatic brain injury. In addition, we evaluate the association of new contralateral lesion formation and the metabolic factors contributing to coagulopathy in the trauma patient.

\section{Methods}

We retrospectively reviewed our neurosurgical operative database between May 2007 and January 2012 inclusive, allowing for a five year interval of inclusion. We searched our surgical procedure database for the terms "craniectomy", "hematoma", "subdural", "epidural", "contusion", "decompression", and "trauma" all separately and in combination. The search returned 252 cases between the above time periods. Images were reviewed for all cases and we included only those patients with decompressive craniectomies for blunt head trauma. These patients were included in the study. Data was then collected from patient charts and imaging. Patient demographics, presenting pathology, presence of new contralateral lesions post craniectomy, and laboratory data upon admission were recorded and analyzed. We recorded data on preoperative $\mathrm{pH}$, bicarbonate $\left(\mathrm{HCO}_{3}\right)$, temperature, serum calcium levels, hematocrit (HCT), platelets, international normalized ratio (INR) and activated partial thromboplastin time (aPTT).

Statistical significance between groups was determined using a one tailed t-test, with significance set at a $\mathrm{p}$ value of less than 0.05 .

For the purpose of this study follow-up was from time of admission until discharge from hospital. Follow-up after discharge from hospital was poorly documented and absent in many cases.

Local research ethics board approval was obtained prior to initiation of this study.

\section{RESULTS \\ Patient Demographics}

A total of 20 patients treated with decompressive craniectomy for blunt traumatic brain injury were identified from our database for the period of May 2007 and January 2012. Fifteen $(75.0 \%)$ were male, and five were female $(25.0 \%)$. The average age was 44.1 years (range: 19 - 72 years). The average Glascow coma score (GCS) on presentation was 6.5 (range: $3-14)$. Ten $(50.0 \%)$ patients presented with a GCS of 3 , two $(10.0 \%)$ with a GCS of 4 , one $(5.0 \%)$ with a GCS of 7 , one $(5.0 \%)$ with a GCS of 12 , two $(10.0 \%)$ with a GCS of 13 , and three $(15.0 \%)$ with a GCS of 14 . One patient $(5.0 \%)$ lacked sufficient records to determine admission pre-operative GCS. Only two patients $(10.0 \%)$ were on systemic anticoagulation for atrial fibrillation pre-operatively, with both having emergent correction of their INR's utilizing fresh frozen plasma. A summary of the demographic data can be seen in Table 1.

All admission cranial imaging consisted of uninfused computed tomography (CT) of the brain, with $5 \mathrm{~mm}$ spacing between consecutive slices. Presenting intra-cranial pathology included acute subdural hematoma $(\mathrm{SDH})$ in 18 patients $(90.0 \%), \mathrm{EDH}$ in one $(5.0 \%)$ patient and temporal contusion in one $(5.0 \%)$ patient. Location of the lesion was right sided in eight $(40.0 \%)$, and left sided in $12(60.0 \%)$. None of the patients displayed contralateral intra-axial or extra-axial pathology on their admission imaging. Follow-up imaging consisted of CT of the brain on post-operative day 1, and again as clinical examination/suspicion dictated.

All patients received craniectomies for evacuation of extraaxial hematomas, except one patient with a large temporal contusion whom received surgery for temporal lobe resection. Craniectomy immediately upon admission occurred in 16 patients $(80.0 \%)$ given their poor neurological examination. The remaining four patients $(20.0 \%)$ had delayed surgery due to relatively good neurological examinations upon admission. The average time from admission until craniectomy in this subgroup was five days (range: $4-9$ days). Average follow-up for this patient population was two months (range: $0.5-3$ months).

Table 1: Patient demographic data

\begin{tabular}{lc}
\hline & Demographic Category \\
\hline \hline Total Number of Patients & 20 \\
Average Age (years) & 44.1 (range: $19-72)$ \\
Number Male & $15(75.0 \%)$ \\
Number Female & $5(25.0 \%)$ \\
Average Presenting GCS & $6.5($ range: $3-14)$ \\
SDH on Presentation & 18 \\
EDH on Presentation & 1 \\
Contusion on Presentation & 1 \\
Number of New Contralateral Lesions & $7(35.0 \%)$ \\
Average 1 Month mRS & 3.15 (range: $1-6)$ \\
\hline GCS = Glasgow Coma Scale, SDH $=$ subdural hematoma, EDH = epidural hematoma, mRS = modified Rankin \\
Scale.
\end{tabular}




\section{Surgical Technique}

For the patients with extra-axial hematomas, the surgical technique was relatively similar across all surgeons involved at our institution. Patients underwent general anesthetic with endotracheal intubation for the procedure. A large myocutaneous flap was elevated on the side of the hematoma. Incisions were predominantly "question mark" shaped. A large craniotomy was then made over top of the hematoma, encompassing the frontal, temporal, and parietal regions of the brain. The extra-axial hematoma was then evacuated utilizing suction and copious irrigation. For those patients with subdural hematomas, the dura was opened in a cruciate fashion. After satisfactory evacuation of the hematoma and hemostasis was ensured, the dural leaflets were laid on top of the cortical surface. Dura was left without suture approximation in six patients, all of whom had a sheet of sterile plastic placed over the cortical surface to allow for protection during future anticipated cranioplasty procedures. In all patients the decision to leave the bone flap off was made intra-operatively due to concerns with cerebral edema and anticipated intracranial pressure issues post-operatively.

The one patient whom received an urgent craniectomy for a temporal lobe contusion had a large linear incision over the temporal region, followed by a craniectomy encompassing the temporal and inferior frontal lobes.

\section{Emergence of New Contralateral Lesions}

We defined new contralateral lesions as the development of intra- or extra-axial lesions contralateral to the operative site that were not present on pre-operative CT imaging. A total of seven patients $(35.0 \%)$ developed new contralateral lesions postcraniectomy. No underlying skull fractures were identified. The average pre-operative GCS for those patients who developed new contralateral lesions post craniectomy was 5.0 (range: 3 14). The average pre-operative GCS for those patients who did not develop new contralateral lesions was 7.3 (range: $3-14$ ). None of the patients who developed new contralateral lesions were on anticoagulants or antiplatelet medications preoperatively. The breakdown of new contralateral lesions can be seen in Table 2.

All patients had the new lesions develop on the day 1 postcraniectomy CT imaging. The new contralateral lesions consisted of EDH in two patients $(10.0 \%)$, acute SDH in two patients $(10.0 \%)$, and temporal lobe contusions in three patients

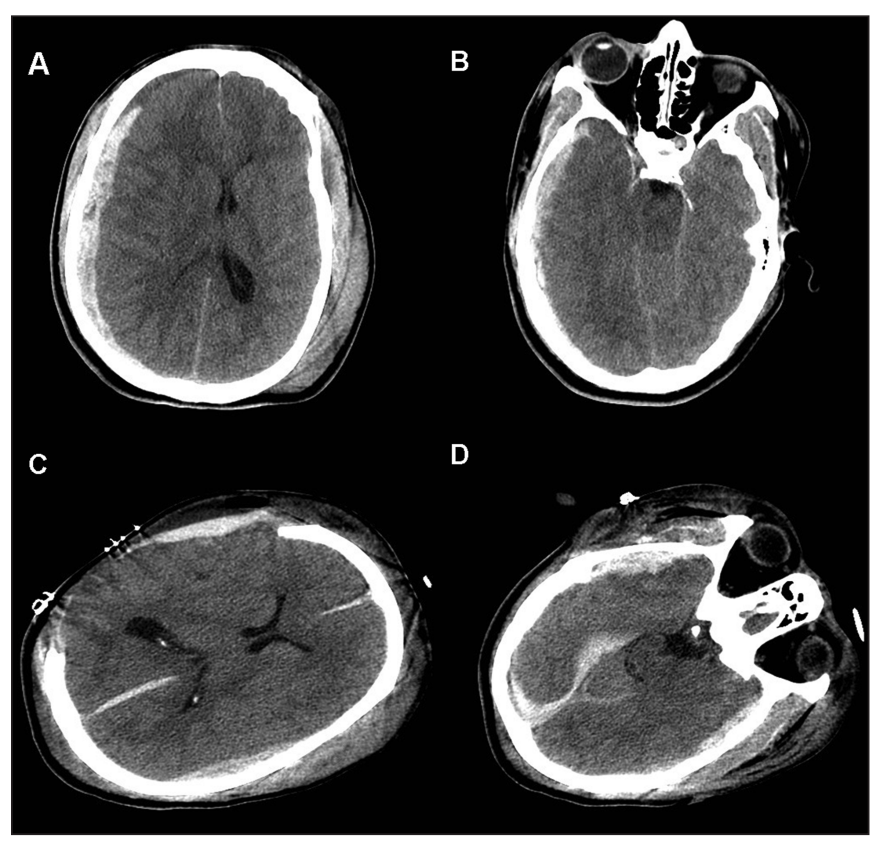

Figure: Neuroimaging Evidence of New Contralateral Extra-axial Lesion Post-Craniectomy. A = pre-operative computed tomography $(C T)$ head displaying a right acute subdural hematoma (SDH) over the cortical surface, with no contralateral lesions. $B=$ pre-operative $C T$ head indicating extension of SDH into right temporal fossa, again no contralateral lesions. $C=$ post-craniectomy CT head done 24 hours later, displaying large right craniectomy. Note new left parietal subdural hematoma has formed. $D$ = post-operative CT head same study as image $C$, notice extension of new left SDH into temporal fossa.

(15.0\%). The maximum thickness of the EDH's that formed was $0.7 \mathrm{~cm}$ and $1.4 \mathrm{~cm}$, located over the left frontal and parietal lobes respectively. The maximum thickness of the acute SDH's that formed was $0.4 \mathrm{~cm}$ and $0.6 \mathrm{~cm}$, located over the right temporal and left frontal-parietal areas respectively. An example of contralateral hematoma formation is displayed in Figure 1. The maximum diameters of the new contralateral contusions were $8.3 \mathrm{~cm}, 2.1 \mathrm{~cm}$, and $1.1 \mathrm{~cm}$ located in right frontal, left temporal and left temporal areas respectively. The craniectomy didn't extend far enough into the right temporal region, and a small

Table 2: New contralateral lesion types and presence of metabolic abnormalities

\begin{tabular}{lccc}
\hline Lesion Type & $\begin{array}{c}\text { Number in Total } \\
\text { Patient Population }\end{array}$ & $\begin{array}{c}\text { Number in Patients with } \\
\text { Metabolic Abnormalities }\end{array}$ & $\begin{array}{c}\text { Number in Patients without } \\
\text { Metabolic Abnormalities }\end{array}$ \\
\hline \hline & 2 & 2 & 0 \\
EDH & 2 & 2 & 0 \\
SDH & 3 & 1 & 2 \\
Contusion & 2 & & \\
\hline
\end{tabular}

$\mathrm{EDH}=$ epidural hematoma, $\mathrm{SDH}=$ subdural hematoma 
persisting right temporal subdural hematoma can be seen. However, the ventricles have returned to midline.

One patient $(5.0 \%)$ required surgical intervention for the new contralateral lesion that formed. This patient was a 24 -year-old male who was admitted post-assault with a GCS of 3 and CT evidence of a large left acute SDH. He was taken emergently for a craniectomy with evacuation of the hematoma. On postoperative day 1 his follow-up CT scan demonstrated a $0.4 \mathrm{~cm}$ contralateral right temporal EDH with mass effect and uncal herniation. He was subsequently taken to the OR for a focal temporal craniotomy with evacuation of the extra-axial collection. He was discharged after three months of hospital stay to our local traumatic brain injury rehabilitation program. His Glasgow Outcome Score (GOS) at one month was 3, and was unchanged at transfer to the receiving rehabilitation facility.

\section{Factors of Coagulopathy and Association with New Lesions}

We recorded data on peri-operative $\mathrm{pH}, \mathrm{HCO}_{3}, \mathrm{HCT}$, platelets, temperature, serum calcium levels INR and aPTT. Normal values for the recorded laboratory values were defined by our institution as: $\mathrm{pH}(7.35-7.45), \mathrm{HCO}_{3}(22-26)$, HCT $(0.4-0.52)$, platelets $\left(140-440 \times 10^{9} / \mathrm{L}\right)$, temperature $(36.5-$ 37.5 degrees Celsius), serum calcium $(2.10-2.60 \mathrm{mmol} / \mathrm{L})$, INR $(0.9-1.1)$, and aPTT $(26-36$ seconds $)$. The patient's laboratory values were documented from samples immediately before craniectomy. Patient $\mathrm{pH}$ and $\mathrm{HCO}_{3}$ levels were determined from arterial blood gas results. Resuscitative attempts had already been underway prior to blood draws and blood gas acquisition. All patients were euthermic during the perioperative period. As summary of the laboratory results for our patients can be found in Table 3.

The average pre-operative $\mathrm{pH}$ for the total patient population in the study was 7.34 (range: $7.14-7.44$ ). The average preoperative $\mathrm{pH}$ of those patients with new contralateral lesions was 7.28 (range: $7.14-7.36$ ), with only one patient having a $\mathrm{pH}$ value above 7.35 . In contrast, the average $\mathrm{pH}$ for those patients that did not develop new lesions was 7.38 (range: $7.33-7.44$ ).
The difference in $\mathrm{pH}$ between the two groups was statistically significant with a t-value of $2.923(\mathrm{df}=18, \mathrm{p}<0.005)$.

Similarly, the average $\mathrm{HCO}_{3}$ level recorded was $20.8 \mathrm{mmol} / \mathrm{L}$ (range: $14-22 \mathrm{mmol} / \mathrm{L}$ ). The average $\mathrm{HCO}_{3}$ level for those patients that developed new lesions was $18.6 \mathrm{mmol} / \mathrm{L}$ (range: 14 - $22 \mathrm{mmol} / \mathrm{L}$ ), while the average recorded in those patients without new lesions was $22.0 \mathrm{mmol} / \mathrm{L}$ (range: 19 - $22 \mathrm{mmol} / \mathrm{L}$ ). The difference in $\mathrm{HCO}_{3}$ between the two groups was statistically significant with a t-value of $2.677(\mathrm{df}=18, \mathrm{p}<0.01)$.

The average HCT level for all patients was 0.382 (range: $0.139-0.457)$. The average HCT for those patients with new contralateral lesions was 0.392 (range: $0.290-0.421$ ), while the average for those without new lesions was 0.376 (range: $0.139-$ 0.452). Within the group of patients that did not develop new lesions, there was one outlier with a HCT value of 0.139 . Removing this patient from the subgroup calculation of average HCT, the average HCT for those without new lesions becomes 0.406 (range: $0.381-0.452$ ). There was no statistical significance between these two groups ( $\mathrm{t}$-value $=0.487, \mathrm{df}=18$, $\mathrm{p}>0.25$ ).

The average peri-operative platelet level was 224 x 109/L (range: $110-319 \times 10^{9} / \mathrm{L}$ ). The average platelet level for those with new lesions was 262 (range: $185-319 \times 10^{9} / \mathrm{L}$ ), while the average for those without new lesions was $203 \times 10^{9} / \mathrm{L}$ (range: 110 - $\left.253 \times 10^{9} / \mathrm{L}\right)$. There was a statistically significant difference between the two groups with lower platelet in those without new contralateral lesions $(\mathrm{t}$-value $=1.953, \mathrm{df}=18, \mathrm{p}$ $<0.05)$.

The average INR for the entire patient population was 1.1 (range: $0.9-1.4$ ). The average INR for those patients with new lesions was 1.1 (range: $1.0-1.3$ ), and the average for those without lesions was 1.1 (range: $0.9-1.4$ ). Only one patient had an INR greater than 1.3. Similarly, the average aPTT for the entire population was 29.4 seconds (range: 26.9 - 36.0 seconds), with the average for those with and without new lesion being 29.1 seconds (range: 26.9 - 35.6 seconds) and 29.5 seconds (range: 28.2 - 36.0 seconds) respectively. There was no

Table 3: Peri-operative metabolic abnormalities and association with new contralateral lesions

\begin{tabular}{|c|c|c|}
\hline $\begin{array}{l}\text { Peri-operative Laboratory } \\
\text { Marker }\end{array}$ & $\begin{array}{c}\text { Patients with New Contralateral } \\
\text { Lesions }(n=7)\end{array}$ & $\begin{array}{c}\text { Patients Without New Contralateral } \\
\text { Lesions }(n=13)\end{array}$ \\
\hline Average pH & 7.28 (range: $7.14-7.36$ ) & 7.38 (range: $7.33-7.44$ ) \\
\hline Average $\mathrm{HCO}_{3}(\mathrm{mmol} / \mathrm{L})$ & 18.6 (range: $14-22$ ) & 22.0 (range: $19-22)$ \\
\hline Average $\mathrm{HCT}^{*}$ & 0.392 (range: $0.290-0.421$ ) & 0.376 (range: $0.139-0.452$ ), $0.406^{*}$ \\
\hline Average Platelets $\left(\times 10^{9} / \mathrm{L}\right)$ & 262 (range: 185-319) & 203 (range: $110-253$ ) \\
\hline $\begin{array}{l}\text { Average Serum Calcium } \\
(\mathrm{mmol} / \mathrm{L})\end{array}$ & 2.06 (range: $1.85-2.26$ ) & 2.02 (range: $1.85-2.27$ ) \\
\hline Average INR & 1.1 (range: $1.0-1.3$ ) & 1.1 (range: $0.9-1.4$ ) \\
\hline Average aPTT (seconds) & 29.1 (range: $26.0-35.6$ ) & 29.5 (range: $28.2-36.0$ ) \\
\hline
\end{tabular}

$\mathrm{HCO}_{3}=$ bicarbonate, $\mathrm{HCT}=$ hematocrit, INR = international normalized ratio, aPTT = activated partial thromboplastin time, $\mathrm{n}=$ number. $*$ This value for HCT for those without new contralateral lesions was calculated after removing the single outlier of 0.139 . 
statistically significant difference between the two groups ( $t$ value $=0, \mathrm{df}=18, \mathrm{p}>0.25)$.

The average serum calcium level for all patients was 2.03 $\mathrm{mmol} / \mathrm{L}(1.85-2.27 \mathrm{mmol} / \mathrm{L})$, with the average for those with and without new lesions being $2.06 \mathrm{mmol} / \mathrm{L}$ (range: $1.85-2.26$ $\mathrm{mmol} / \mathrm{L}$ ) and $2.02 \mathrm{mmol} / \mathrm{L}$ (range: 1.85 - $2.27 \mathrm{mmol} / \mathrm{L}$ ) respectively. There was no statistically significant difference between the two groups ( $\mathrm{t}$-value $=0.602, \mathrm{df}=18, \mathrm{p}>0.25)$.

Five of the seven patients $(71.4 \%)$ with new contralateral lesions post-craniectomy had abnormalities (as described above) on their laboratory results that have been know to be attributable to coagulopathy in the trauma patient. Four of these patients $(57.1 \%)$ with new lesions had two or more abnormal laboratory results, with two $(28.6 \%)$ having three or more abnormalities.

In comparison those patients without new contralateral lesion emergence post-craniectomy, 8 of $13(61.5 \%)$ had laboratory abnormalities in the peri-operative period. Five patients $(38.5 \%)$ without new contralateral lesions had two or more laboratory abnormalities identified. There was no statistical significance between the number of patients with metabolic abnormalities and new lesions compared to those with metabolic abnormalities without new lesions (t-value $=0.627, \mathrm{df}=18, \mathrm{p}>0.25$ ).

\section{Complications of surgery}

Complications post-craniectomy included: seven $(35.0 \%)$ new contralateral hematomas $(35.0 \%)$, four $(20.0 \%)$ patients with shunt dependant hydrocephalus, one $(5.0 \%)$ bone flap infection upon cranioplasty, and one $(5.0 \%)$ ventriculoperitoneal shunt infection.

\section{Outcomes at one month}

Due to lack of follow-up data documented, we were only able to obtain follow-up until discharge from hospital care. Average in-hospital follow-up for this patient population was two months (range: $0.5-3$ months). The average $\mathrm{mRS}$ for all patients was 3.2 (range: 0 - 6). Modified Rankin Scale scores of 1, 2, 3, 4, 5, and 6 were recorded in $5(25.0 \%), 0(0 \%), 8(40.0 \%), 4(20.0 \%)$, $0(0 \%), 3(15.0 \%)$ patients respectively. One $(5.0 \%)$ patient was discharged home from hospital, while $14(70.0 \%)$ were transferred to rehabilitation facilities and $3(15.0 \%)$ to long-term personal care homes. Three $(15.0 \%)$ patients died during their hospital stay due to their severe neurological injury. Only one $(5.0 \%)$ patient that died had displayed new contralateral lesion formation after craniectomy.

\section{Discussion}

Decompressive craniectomy in the setting of traumatic brain injury is a controversial topic with ongoing debate in the literature regarding the benefit in reducing morbidity and mortality. Few randomized control trials exist looking at decompressive craniectomy plus medical management compared to standard medical management alone. The recent publication of the multi-center randomized control trial, Decompressive Craniectomy in Diffuse Traumatic Brain Injury (DECRA) Trial, has indicated a benefit to intracranial pressure (ICP) with craniectomy in the adult population ${ }^{14}$. However, unfavorable outcomes were increased in the surgical group. In contrast, the only randomized study of decompressive craniectomy in the pediatric population has displayed some potential benefit of craniectomy in functional outcome ${ }^{15}$. Other adult retrospective reviews have echoed this potential benefit in reducing mortality and morbidity seen in the pediatric population ${ }^{16}$. The RESCUEicp study ${ }^{17}$ is another multi-center randomized control trial that is active and may clarify/resolve these previous conflicting conclusions. Current opinions surrounding this surgical procedure view it as a "last resort", once medical management has failed ${ }^{18}$.

The goal of this invasive surgical procedure is to provide reduction in poorly controlled ICP, with the hope of improved survival and functional outcomes. Numerous studies have displayed the benefit of craniectomy in improved cerebral compliance, ICP reduction and successful maintenance of cerebral perfusion pressure (CPP) goals ${ }^{19-21}$. Despite these benefits, the impact on morbidity and mortality with craniectomy has not been clearly established.

The complications of craniectomy are well described in the setting of traumatic brain injury ${ }^{1}$. New contralateral extra-axial hematoma formation has been described in up to $7 \%$ of patients undergoing decompressive craniectomy for traumatic brain injury ${ }^{7}$. The theory behind this stems from a rapid decrease in ICP post-craniectomy leading to expansion of underlying unidentified contralateral pathology, either intra- or extra-axial in location. Furthermore, presence of coagulopathy has been attributed to poor outcomes in neurocritical care settings ${ }^{8-11}$, directly associated with progression and emergence of intracranial lesions in the setting of traumatic brain injury ${ }^{8,9}$.

Given the complex nature of both the general trauma patient and neurotrauma patient, there are numerous factors that can contribute to derangements in effective coagulation ${ }^{12,13}$. Acidosis with a $\mathrm{pH}<7.1$ can lead to alteration in platelet function, and impaired thombin generation ${ }^{22}$. Hypocalcemia $(<0.9 \mathrm{mmol} / \mathrm{L})$ leads to impairment of conversion of fibrin to thrombin, and increases fibrinogen denaturation ${ }^{23}$. Low HCT $(<30 \%)$ levels have been negatively associated with bleed time and platelet counts ${ }^{12,13}$. Hypothermia ( $<34$ degrees Celsius) can lead to clotting enzyme and platelet dysfunction. Combinations of the aforementioned abnormalities further increases the risk of platelet and coagulation cascade dysfunction.

Our study was focused on defining the incidence of new contralateral intra- and extra-axial lesions post decompressive craniectomy in blunt trauma patients. In addition, we were interested in whether the metabolic abnormalities that contribute to trauma related coagulopathy displayed any relation to the incidence of new lesions.

We identified 20 patients between May 2007 and January 2012 who underwent craniectomy for blunt traumatic brain injury. Clinical follow-up was limited to their acute hospital stay on the neurosurgical service. We were able to demonstrate an incidence of $35 \%$ for new contralateral lesion formation postcraniectomy. This is slightly higher than described in previous studies $^{7}$. The presence of pre-operative oral antiplatelet or anticoagulant agents was not associated with new contralateral lesion formation post-operatively.

Metabolic derangements in the form of abnormalities in $\mathrm{pH}$, $\mathrm{HCO}_{3}$, serum calcium, temperature, platelets, $\mathrm{HCT}$, INR and aPTT were recorded and appeared to be associated with the incidence of new contralateral lesion formation. The patients 
with new contralateral lesions displayed on average lower $\mathrm{pH}$, $\mathrm{HCO}_{3}$, and HCT (with removal of one outlier as described previously) levels when compared to those without new lesions. The difference in mean $\mathrm{pH}$ and $\mathrm{HCO}_{3}$ between patients with new contralateral lesions and those without were found to be statistically significant, with $\mathrm{p}<0.005$ and $\mathrm{p}<0.01$ respectively. In addition, five of the seven patients (71.4\%) with new contralateral lesions had one or more metabolic derangements, with four $(57.1 \%)$ having two or more abnormal results. In contrast, 8 of $13(61.5 \%)$ patients without new lesion postcraniectomy had laboratory abnormalities in the peri-operative period, with only five (38.5\%) demonstrating two or more abnormalities. The difference in the number of patients with metabolic derangements who developed new lesions compared to those without new lesions was not found to be statistically significant, though we suspect this to be related to the small patient population available for study.

These results support our suspicion that in the setting of closed head injury, those patients with new contra-lateral lesion formation post decompressive craniectomy tend to have more metabolic abnormalities associated with trauma related coagulopathy. In addition, the severity of the metabolic derangements is worse in the patient group with new contralateral lesion formation. This potentially implicates mild platelet and coagulation cascade dysfunction secondary to metabolic abnormalities leading to the formation of these lesions. The overall severity of the metabolic derangements displayed in our patient population was relatively mild and is likely a result of early resuscitation attempts. In addition, the underlying cause of these lesions may be a combination of metabolic derangements and a "pressure release" phenomenon that occurs during craniectomy, allowing contralateral lesions to grow after relieving potential tamponade pressure. Furthermore, the mean presenting GCS for those that developed new lesion was lower than those without new contralateral lesion, which could indicate the severity of injury was much worse in the new lesion group and thus they were predisposed to develop these lesions regardless. Nevertheless, this relationship seen with the metabolic abnormalities is present in our study.

Despite these interesting results there are several limitations of our study. First, the small patient population leaves it difficult to understand the significance of our association between the metabolic derangements described and the incidence of new contralateral lesions post-craniectomy, despite the statistical significance in the difference in $\mathrm{pH}$ and $\mathrm{HCO}_{3}$ between the two groups. Furthermore, it makes the results of this study difficult to generalize to all patients undergoing decompressive craniectomy for traumatic brain injury. Second, the retrospective nature of the study poses limitations on the quality of the data accrued and the inherent patient selection biases associated with retrospective studies. This can be seen in our limited long term follow-up data. Third, the relatively small patient population subjected to decompressive craniectomy suggests that our institutional approach to this operation employs it as a last resort for ICP management and, in particular, mainly for patients with defined intra- or extra-axial lesions. Thus, the conclusions of this small series cannot be extended to those patients undergoing decompressive craniectomy for diffuse cerebral edema in the setting of trauma. In addition, those patients that underwent craniectomy in our study form a highly selected patient population with young average age and early arrival to neurosurgical care, thus potentially adding further bias. Finally, the overall severity of metabolic derangement in our patients with new contralateral lesions was mild. One could argue that this further clouds the argument for the association between these abnormalities and new lesion formation in our study, and leaves the real significance of the described findings still unclear. However, as mentioned above, we believe the laboratory values we observed are a result of effective pre-hospital and emergency department resuscitation efforts, prior to blood sampling. We believe that the association between metabolic derangements and new contralateral lesion formation could be clearer if we had laboratory samples from earlier on in the resuscitation, or preresuscitation.

Despite the acknowledged limitations, we believe our study further defines the incidence of new contralateral lesion formation post-craniectomy in blunt head injury. In addition, we have been able to demonstrate a possible relationship between peri-operative metabolic abnormalities known to be associated with trauma-related coagulopathy and the incidence of new contralateral lesion formation after craniectomy. Further studies looking into prospectively maintained head injury databases could potentially display a more robust relationship.

\section{Conclusions}

The incidence of new contralateral intra- and extra-axial lesions post- decompressive craniectomy for blunt head injury is $35.0 \%$ in our experience, with the majority being non-operative. In addition, there may be a relationship between the metabolic derangements associated with the coagulopathy of trauma and the incidence of new contralateral lesions post-craniectomy for blunt head injury, though further study is warranted.

\section{REFERENCES}

1. Stiver SI. Complications of decompressive craniectomy for traumatic brain injury. Neurosurg Focus. 2009; 26(6):E7.

2. Nalbach SV, Ropper AE, Dunn IF, Gormley WB. Craniectomyassociated progressive extra-axial collections with treated hydrocephalus (CAPECTH): redefining a common complication of decompressive craniectomy. J Clin Neurosci. 2012; 19: 1222-7.

3. Li X, van Holst H, Kleiven S. Decompressive craniectomy causes a significant strain increase in axonal fiber tracts. J Clin Neurosci. 2013; 20:509-13.

4. Takeuchi S, Takasato Y. Contralateral acute subdural hematoma after surgical evacuation of the initial hematoma: two case reports and review of the literature. Turk Neurosurg. 2013; 23 (2):294-7

5. Shen J, Pan JW, Fan ZX, Zhou YQ, Chen Z, Zhan RY. Surgery for contralateral acute epidural hematoma following acute subdural hematoma evacuation: five new cases and a short literature review. Acta Neurochir. 2013; 155:335-41.

6. Wen L, Li QC, Wang SC, et al. Contralateral haematoma secondary to decompressive craniectomy performed for severe head trauma: a descriptive study of 15 cases. Brain Inj. 2013; 27(3): 286-92.

7. Yang XF, Wen L, Shen F, et al. Surgical complications secondary to decompressive craniectomy in patients with a head injury: a series of 108 consecutive cases. Acta Neurochi (Wien). 2008; 150:1241-8.

8. Harhangi BS, Kompanje EJO, Leebeek FWG, Maas AIR. Coagulation disorders after traumatic brain injury. Acta Neurochi (Wien). 2008; 150:165-75. 
9. Maegele M. Coagulopathy after traumatic brain injury: incidence, pathogenesis, and treatment options. Transfusion. 2013; 53: (Suppl)28S-37S

10. Salehpour F, Bazzazi AM, Porhomayon J, Nader ND. Correlation between coagulopathy and outcome in severe head trauma in neurointensive care and trauma units. J Crit Care. 2011; 26: 352-6.

11. Stein SC, Spettell C, Young G, Ross SE. Delayed and progressive brain injury in closed-head trauma: radiological demonstration. Neurosurgery. 1993; 32(1):25-30.

12. Hess JR, Brohi K, Dutton RP, et al. The coagulopathy of trauma: a review of mechanisms. J Trauma. 2008; 65:748-54.

13. Lier H, Krep H, Schroeder S, Stuber F. Preconditions of hemostasis in trauma: a review. The influence of acidosis, hypocalcemia, anemia, and hypothermia on functional hemostasis in trauma. J Trauma. 2008; 65:951-60.

14. Cooper DJ, Rosenfeld JV, Murray L, et al. Decompressive craniectomy in diffuse traumatic brain injury. N Engl J Med. 2011; 364(16): 1493-502.

15. Taylor A, Butt W, Rosenfeld J, et al. A randomized trial of very early decompressive craniectomy in children with traumatic brain injury and sustained intracranial hypertension. Child's Nerv Syst. 2001; 17:154-62.

16. Pereyra C, Mori LB, Schoon P, et al. Decompressive craniectomy and brain death prevalence and mortality: 8-year restrospective review. Transplant Proc. 2012; 44:2181-4.
17. Hutchinson PJ, Corteen E, Czosnyka M, et al. Decompressive craniectomy in traumatic brain injury: the randomized multicenter RESCUEicp study (www.RESCUEicp.com). Acta Neurochir Suppl. 2006; 96:17-20.

18. Sahuquillo J, Marinez-Ricarte F, Poca MA. Decompressive craniectomy in traumatic brain injury after the DECRA trial. Where do we stand? Curr Opin Crit Care. 2013; 19:101-6.

19. Bor-Seng-Shu E, Figueiredo EG, Fonoff ET, Fujimoto Y, Panerai RB, Teixeira MJ. Decompressive craniectomy and head injury: brain morphometry, ICP, cerebral hemodynamics, cerebral microvascular reactivity, and neurochemistry. Neurosurg Rev. 2013; 36(3):361-70.

20. Timofeev I, Czosnyka M, Nortje J, et al. Effect of decompressive craniectomy on intracranial pressure and cerebrospinal compensation following traumatic brain injury. J Neurosurg. 2008; 108:66-73.

21. Bor-Seng-Shu E, Figuieredo EG, Amorim RLO, et al. Decompressive craniectomy: a meta-analysis of influences on intracranial pressure and cerebral perfusion pressure in the treatment of traumatic brain injury. J Neurosurg. 2012; 117: 589-96.

22. Martini WZ, Pusateri AE, Uscilowicz JM, Delgado AV, Holcomb JB. Independent contributions of hypothermia and acidosis to coagulopathy in swine. J Trauma. 2005; 58:1002-9.

23. Reganon E, Vila V, Aznar J. Effect of calcium ions on fibrin get formation in normal plasma. Thromb Res. 1984; 35:365-9. 